\section{The New Challenges}

\author{
Herwig Schopper \\ EPS President
}

\begin{abstract}
Society needs science, both basic and applied. To fluorish, both aspects need forseeable conditions. Convincing the public and politicians will require much effort on the part of EPS in addition to the vital tasks that can be undertaken by a learned society.
\end{abstract}

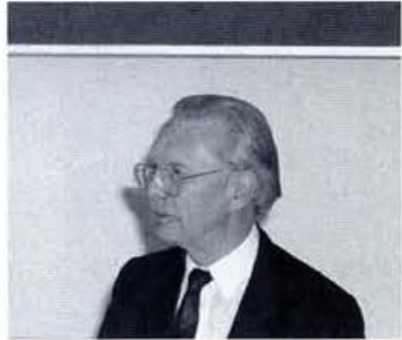

Herwig Schopper is seen here addressing the EPS Council in March 1995 shortly after being elected EPS President.
During the cold war, science and physics were seen as essential for national security. This perspective has changed in the minds of politicians and the public. A major effort in weapons development is now considered unnecessary, and defence budgets providing, directly or indirectly, important funding for technology and even for fundamental physics, are being cut considerably. In one way we should be happy about these trends; but on the other hand the consequences for science remain difficult to assess, and a new equilibrium has to be found. Profound changes are still taking place; we must recognise them and react. In doing so, EPS will have to tackle a much wider range of challenges.

We can detect everyday that the cold war is being replaced by an economic struggle. Different parts of the world strive for economic supremacy to guarantee their welfare. To Europe, North America and Japan we shall have to add very soon the "small tigers" in the Far East as well as China. Science and technology are recognised as essential bases for long-term economic competitiveness. However, politicians are also concerned with short-term success and contrary to the long-term aspects, claim that science cannot contribute to solving today's burning problems, such as unemployment and state deficits. Consequently, cuts in resources for science are quite common.

Another evolution (should I say crisis?) concerns teachers and young physicists. Apart from some minor ripples in the job market, physicists have been in demand for many decades. Today, partly because of the developments mentioned above, but also because of a certain "overproduction", even excellent young physicists have difficulty finding positions.

\section{A Deeper Crisis}

However, the West is confronted with a much deeper crisis. Since the Renaissance, logical thinking and rationalism were viewed as great achievements, and democracy and the search for truth were considered preeminent. Science and technology developed on this basis, and changed the shape of humanity. Indeed, only they made it possible for slavery to be abandoned and thanks to them many enjoy a standard of living unthinkable a century ago. Unfortunately, insufficient efforts were made to minimize negative effects. As a result, and because of other trends, we are surrounded today by a frightening anti-rationalist movement mixed up with pseudo-scientific beliefs. These "post-modernist" critiques seem to grow daily. As a famous German environmentalist said: "I do not need facts; I am concerned!" Such an attitude makes it almost impossible to discuss rationally the need for technological development and the measures to prevent negative effects on, for instance, the environment. So newspape articles about astrology fill many more pages than scientific issues, and emotionbased movements, strange sects, creationism, etc. are much more fashionable than rational activities.

The post-modernistic critics claim that modern science has badly misled Western civilisation by providing false models, such as the primacy of rationalism and the search for objective truth - believed to be illusory since truth is only a socially constructed fiction. But history has shown repeatedly that a dissatisfaction with science and its view of the world can turn into a rage that links up with far more sinister movements.

\section{The Future Needs Physics}

The adversity, or at least the disinterest, towards science in general and physics in particular is surprising if one accepts that our standard of living owes much to breathtaking technological developments over the last 200 years. Humane working conditions and the like are achievements which were restricted in the past to a very small, privileged class. Social ideas may have contributed, but were certainly insufficient.

Our technological evolution was, of course, founded on basic research. The contributions from physics were essential since apart from generating the results vital for new technologies, they also played crucial roles as interdisciplinary links by providing new research techniques which have influenced strongly other fields.

It has become fashionable for the political establishment in many countries to emphasize the importance of applied research, technology transfer and the creation of new products, notwithstanding the view expressed by some that technology will become less important since services of all kinds rather than production will be decisive for economies. But who provides the products which are the bases for new services?

It is unfortunately more difficult to demonstrate the usefulness of physics relative to other scientific fields since physics satisfies requirements indirectly through technology. Everybody knows what a lawyer, medical doctor or engineer does; but what about a physicist? This lack of knowledge derives partly from the fact that there is no physics industry.

Nevertheless, physics research will be absolutely vital for solving some of the urgent problems of society such as energy production, distribution and saving, information and communications technology, and environmental issues. But apart from providing the basis for technical applications, physics forms part of human culture. Driven by the curiosity to find the principles which determine Nature, physics research has profoundly changed human thinking and has established new approaches in the search for truth. We recognize that final truth will not, and cannot, be found. But the scientific method nevertheless brings us closer to it. There are no revolutions in physics in the sense that old, well-founded knowledge is destroyed. Instead, the limits of validity are restricted: a new theory confirmed by experiment encompasses the old one. The outcome is that physics has contributed more to our concept of the world than many other sciences. Only the discoveries in biology of evolution and the role of DNA have perhaps had an equally strong influence on our way of thinking.

In view of the practical and cultural values of physics for society, in an ideal, or at least more reasonable, world it should not be scientists who go begging for support but rather politicians in formulating their requests to science.

\section{Action Needed}

One of the strengths of physicists is that they learn how to respond to new situations. Indeed, major progress in our field is always 


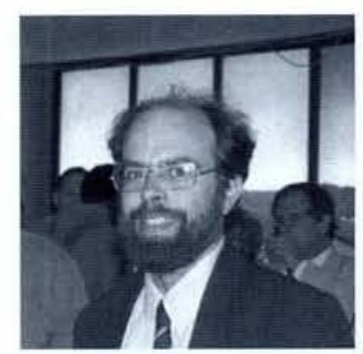

Upper: Peter Melville from Birmingham chairs the newly established Interdivisional Group for Applied Physics and Physics in Industry.

Lower: Raf Dekeyser, on the left, from Leuven chairs the Action Committee for Physics and Society. He is seen here with A.V. Slobodyanyuk from Kiev at the EPS Council in March.

coupled to change, both in concepts and experimental techniques. Rabi once said: "Physicists are the Peter Pans of the human race". We also learn that changes should be introduced only when necessary, and not as an objective in themselves. Heisenberg once told me that revolutions and their results usually do not last since they are introduced too rapidly; he felt that physics teaches us that only adiabatic transitions lead to a stable state.

Given the new challenges, one asks what changes are really necessary and how they should be introduced. Some of the challenges are so fundamental that a change in mentality will be unavoidable; this is sometimes difficult to accept, even for physicists. But I am confident that physicists will demonstrate sufficient intellectual flexibility to adapt to the new realities and even be leaders. EPS has a vital role to play, so I want to discuss some of its more important tasks.

\section{Take science to the general public}

It is partly our fault if wrong impressions about physics flourish. Scientists have contributed mightily to the specialization of knowledge that also threatens to tear physics into non-communicating branches whose relevance is sometimes not obvious. I still believe in the unity of physics, but to preserve it requires an effort which few are prepared to make. And we are not doing enough to inform our fellow citizens and to communicate with them. The situation has certainly improved thanks to the efforts of national physical societies, but much remains to be done. We possibly make the mistake that we want to tell the public what we think it should know while not asking ourselves what it would perhaps like to know.

The presentation of science in the media, in particular on television, deserves great attention. Meetings organized by the German Physical Society and and by CERN with top representatives of the media gave depressing results. Even the government-financed TV channels, faced with competition from private channels, give great weight to audience levels. Some predict that in several years there will practically be no scientific programmes, except those dealing with animals and medicine, since they interest only about $6 \%$ of spectators. Special cultural channels will reach a very limited number of people. So learned societies are faced with a difficult but enormously important task that will require great effort and much patience.

\section{Reinforce links with applied research}

I believe that the distinction between basic and applied physics is to a large

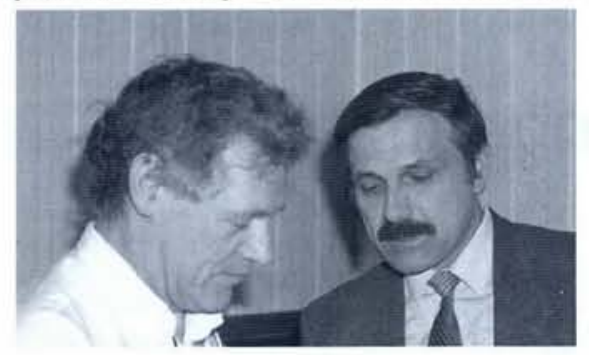

extent arbitrary and even destructive. One must certainly avoid being too dogmatic applications of a specific piece of research are missing. But we can say that the results of curiosity driven research have often and within a short time led to major changes in daily life. For example, there is: electromagnetism - the basis of electrical engineering in its many forms; stimulated emission - an abstract notion in quantum mechanics upon which lasers are based; nuclear fission and fusion - demonstrating via its two main applications (nuclear reactors and atomic bombs) that science can be used for the welfare or to the detriment of mankind. Moreover, instrumentation developed for basic research has often opened up new avenues for technology (e.g., the tunnelling microscope).

On the other hand, applied research which usually concentrates on the question "What can and must be done so that something works?" has provided new insights. D'Alembert wrote as long ago as 1751 that: "The discovery of the compass has brought to humanity as much benefit as the understanding of its properties will contribute to physics". This is also the case for aeroplanes (a better understanding of hydrodynamics) and high-temperature superconductors (new light on the mechanism of superconductivity).

The close relation between applications and curiosity driven research does not guarantee that the transfer of knowledge func-

\section{LONG-TERM EPS TASKS}

- Address the general public and the political environment to help explain the importance of physics for the future of society.

- Promote physics by means of conferences, workshop, studies, etc.

- EPS publications; qualification of conferences and physics publications.

- Help to improve relations between basic research and technology.

- Contribute to improving pre-university and university teaching.

- Promote international cooperation, especially east-west collaboration, and improve relations with developing and evolving countries.

- Foster dialogue between the various parts of physics (large science - small science; university - industry).

- Undertake special actions as required. because indicators for the relevance to tions automatically. Effort must be made by physicists in both camps, where effective technology transfer depends more on the mentality of people than on institutionalized cooperation. I see here one of the most important tasks of the recently established Interdivisional Group for Applied Physics and Physics in Industry (IGAPPI). It should develop contacts between all fields of basic research and applications. The recruitment of Individual Ordinary Members (IOMs) in industry may be very effective in establishing closer links at a personal level.

\section{Change mentalities at universities}

Much basic research is performed in universities, and it is generally understood that the major part should in principle remain independent of commercial influences, open to the free exchange of results and integrated into teaching. However, university professors have mainly cared about physicists who became researchers in universities or large laboratories. We paid much less attention to students who would move into industry or out of physics. The situation has dramatically changed: many students leaving universities will have to find jobs in industry or outside research (marketing, customer services, administration, environmental activities, etc.). Most new opportunities require the methodology which physicists learn, as well as mental flexibility and an understanding of how to treat complex systems where a broad knowledge of Nature's basic laws is vital.

But, scientific knowledge is no longer sufficient for a successful career. Human values have become as important. Leadership and the ability to motivate collaborators, to "sell" achievements, to cooperate in teams, to undertake interdisciplinary work, and to hold one's ground in international enterprises are as essential as factual knowledge.

Our universities are not yet taking sufficient account of these changes. Physicists leaving universities are often considered too specialised to be effective in situations requiring solutions of complex, multidisciplinary problems. Academic research, in not being submitted to a large extent to restrictions involving cost efficiency, time schedules and cooperative working, operates under conditions that are quite different from those for industrial research. If universities want to have the support of society they will have to adapt. But introducing the changes involves not only details of curricula; mentalities will also have to change. This will require a major effort and physical societies can play an important role.

\section{Improve physics teaching in schools}

We are living in a world where daily life is determined to a large extent by technology. It seems to be of the utmost importance that citizens understand at least the principles 


\section{Immediate Actions}

- Expand the activities of the EPS Divisions and Interdivisional Groups in the light of the revised EPS Constitution. - Develop a new format for Europhysics News, including an enlarged Editorial Board.

- Establish a new approach for east-west cooperation adapted to the evolution of the situation in the various countries.

- Improve relations between basic research and industry through the Interdivisional Group for Applied Physics and Physics in Industry.

- Under the auspices of the Physics and Society Action Committee, survey the job situation for physicists and provide help in finding positions, especially for young physicicts.

- Relocate the EPS Secretariat and streamline services.

underlying these technologies. Otherwise how can they or politicians form an opinion concerning decisions that have to be taken in favour of or against a particular technology? Without some basic understanding there is a danger that rational debates are replaced by emotional controversies (examples include nuclear power and the biological effects of electromagnetic waves).

So more attention should be given to the training of those who will not stay in science by focussing on teaching in elementary and secondary schools. The deep-rooted misconception that technology is an evil can only be changed through education starting at the elementary level. An educational programme for teachers has been organized by the new EPS Forum on Education and I encourage all concerned to strengthen their efforts.

\section{Enhance employment opportunities}

If we wish to improve teaching we of course have to ask and answer the question: "Teaching for what?" Employment prospects for physicists need much more attention in EPS. The golden era when practically all physicists found jobs without too much difficulty have gone and most forecasts show that the situation will not change in the near future. Modifying the way physics is taught at universities, as mentioned above, will improve the chances for physicists in competition with other professionals.

Students will increasingly seek advice on jobs in different "markets" and I consider it a necessary activity of EPS to help students in this respect. There are many ways to do this, including meetings between industrialists and students and the generation of information about industry's requirements, including statistical data on positions and the future prospects. Some national physical societies are active in this area, and an updating of a review of the European situation is being prepared by the EPS Action Committee for Physics and Society. This is an extremely important role for EPS in view of the necessarily increased mobility of physicists across national frontiers.

\section{Develop international cooperation}

International cooperation has been an integral element of physics and of EPS for a long time. It has promoted the progress of science and, equally important, understanding and confidence among people of different nations, cultures, political systems, race, and religion. Indeed physics has been spearheading such developments independently of a sometimes rapidly changing political climate. International cooperation is more necessary then ever now that the cold war has ended, but many new problems with very different features have arisen. In particular:

- We sadly notice a backlash with regard to tolerance and mutual understanding.

- International cooperation, even in applied research, is essential and should be strengthened in spite of economic competition since joint effort is needed to overcome some of mankind's major problems.

- Some major activities intrinsically require international collaboration (e.g., climatic change research, oceanography, earth sciences, astronomy and astrophysics). Others are simply too expensive to be undertaken by a single large country or region (e.g., the ITER fusion device; the space station; Mars missions; CERN's LHC).

- East-West cooperation, which attracted considerable attention with the end of the cold war, remains a crucial topic even after having met with some disappointments.

- North-South cooperation, not only with poor countries but also with evolving countries, will become more important.

EPS has established several activities that promote European cooperation, notably

\section{Physics Action Council}

The Physics Action Council (PAC) was established in 1993 by UNESCO (the "S" in the acronym stands for science!) to help reinvigourate relations with the physics community [EN 25 (1994) 84]. Members, although nominated ad personam, were recruited mainly from regional physical societies. PAC has working groups on large facilities, communications and education and it also aims to make the voice of the physics community heard in governmental organizations. For instance, the large facilities working group will hol a high-level meeting in June with the Central European Initiative (the government-level collaboration that aims to promote the development of science in central Europe). The Director-General of UNESCO agreed recently to extend the Council for a third year to give more time to decide upon the conclusions of a final report which will be submitted at the end of 1995. in central and east Europe. But the Society's role is also becoming more important in a world-wide context. While there are many bilateral contacts between national physical societies, in addressing global problems our partners in other parts of the world prefer to deal with a single European representative. A good example is the Physics Action Council (PAC; see insert) established last year by UNESCO.

\section{Streamlining EPS}

A major effort is being made to make the operations of EPS as efficient as possible so that the Society can fulfil its many tasks with the limited personnel and financial resources. This is of particular importance in view of the new objectives envisaged by the revised EPS Constitution. The three measures that make EPS much more attractive are:

- The possibility for all members of national physical societies to participate in Divisional activities.

- Intensification of the activities of the Interdivisional Groups and Action Committees, with eventually new ad hoc groups for specific activities.

- A new concept for Europhysics News which is now being delivered to members of national societies (except for the UK's Institute of Physics and the German Physical Society which publish the Society's information to members in their own bulletins).

In order to find the necessary resources for these and other tasks a major effort will be made to streamline administrative services. Moving the Secretariat from Geneva to a less expensive location will be the most important action. The production of Europhysics News in collaboration with a publishing house is also envisaged.

An effort will also be made to provide full information to the national societies concerning the various EPS activities and the resources involved. This will place the societies in a better position in evaluating the distribution of resources.

I appeal to all our members, be they IOMs or members of a national society, to help us with active cooperation and constructive criticism. Together we can meet the goals of EPS in promoting our field of science, not only because we appreciate it so much but also for the benefit it brings to society at large.

\section{5th GENERAL CONFERENCE OF THE CONDENSED MATTER DIVISION OF EPS} 22-25 April 1996 Baveno-Stresa, Lago Maggiore, Italy

For information and to receive 2 nd circular (in October 1995), contact:

Organizing Secretariat, CMD-EPS '96 PRAGMA

Via S. Giovanni in Borgo, 4, 1-27100 Pavia Tel. +39-382-302859- Fax +39-382-276 97 Information: EurophysNet at http://epswww.epfl.ch 